\title{
Crystallization and Melting Behavior in Blends of Poly(3-hydroxybutyrate-co-3-hydroxyvalerate)s with a Narrow Composition Distribution
}

\author{
Naoko Yoshie, Hiroyuki Menuu, Hidenori Sato, and Yoshio Inoue \\ Department of Biomolecular Engineering, Tokyo Institute of Technology, \\ Nagatsuta, Midori-ku, Yokohama 226, Japan.
}

(Received September 6, 1995)

\begin{abstract}
Crystallization and melting behavior of blends of poly(3-hydroxybutyrate-co-3-hydroxyvalerate) (P(HBco-HV)) copolyesters, which were prepared by compositional fractionation of bacterially synthesized $\mathrm{P}(\mathrm{HB}-\mathrm{co}-\mathrm{HV})$ and have a narrow composition distribution, have been investigated and compared to those of $\mathrm{P}(\mathrm{HB}-\mathrm{co}$ - $\mathrm{HV})$ before fractionation. Analysis of DSC melting thermograms and spherulite growth rate indicates four situations that might arise from the blend. These are: (i) An isomorphous crystalline phase being formed from the miscible melt. (ii) Two crystalline phases observed in situations (i) and (iii) being formed from the miscible melt. (iii) A crystalline phase of the component polyester having the largest crystallization rate being partitioned from the miscible melt. (iv) Two crystalline phase similar to the pure components being formed from the immiscible melt. Most bacterial $\mathrm{P}(\mathrm{HB}-\mathrm{co}-\mathrm{HV})$ copolyesters are in situation (i) and are indistinguishable from $\mathrm{P}(\mathrm{HB}-\mathrm{co}-\mathrm{HV})$ having a narrow composition distribution. Some bacterial $\mathrm{P}(\mathrm{HB}-\mathrm{co}-\mathrm{HV})$ copolyesters, which have a extremely broad composition distribution, show behavior different from $\mathrm{P}(\mathrm{HB}-\mathrm{co}-\mathrm{HV})$ with a narrow one. We need to take account of the details of composition distribution of these $\mathrm{P}(\mathrm{HB}-\mathrm{co}-\mathrm{HV})$ samples. Especially in situation (iii), we are apt to mistake the properties of the partitioned crystals for those of the isomorphous crystals. An observation of a single $T_{\mathrm{m}}$ is not sufficient to confirm the isomorphous crystals.

KEY WORDS Composition Distribution / Polymer Blend / Poly(3-hydroxybutyrate-co-3-hydroxyvalerate) /
\end{abstract}

Recently, productions of various hydroxyalkanoate copolymers (PHAs) by bacterial fermentation have been reported. The importance of this family owes to biodegradability combined with thermoplasticity. Poly(3hydroxybutyrate) (PHB) and its copolyesters with 3hydroxyvalerate (PHB-HV) are the best-known members of this family. ${ }^{1-3}$ A variety of properties ${ }^{4,5}$ such as melting temperature, ${ }^{6-8}$ solid-state structure, ${ }^{6,9,10-12}$ crystallization behavior, ${ }^{11,13}$ mechanical properties, ${ }^{14,15}$ and enzymatic degradation processes, ${ }^{16}$ have been studied for this copolyester. Most of the studies focused on the dependence of these properties on the comonomer composition. These properties certainly vary with the $\mathrm{HV}$ content. In these studies, however, a narrow composition distribution was expected without any careful consideration.

Every copolymer is considered to be a kind of polymer blends by its nature, that is, a copolymer material is composed of molecules over a range of comonomer compositions. In general, the range in a synthesized copolymer is believed to be very narrow. We can treat a copolymer material as a mass of identical macromolecules and the average composition as a composition of every molecule. In this study, we refer to only the copolymer with a narrow composition distribution as a pure copolymer. However, we found recently that bacterial PHB-HV copolyesters have a complex feature of composition distribution, i.e., their composition distribution is extremely broad and/or has many peaks over a wide composition range. ${ }^{17}$ We can regard bacterial PHB-HV copolyesters as a blend of the several pure copolyesters with a different composition. The analyses of both average composition and composition distribution are needed for physical characterization of such
PHB-HV copolyesters. However, the rigid relations between various properties and composition distribution have not been made clear for these copolyesters.

Some information about these relations is expected to be provided by the studies on blends of PHB and PHB-HV and on mixtures of the copolyesters. Some studies in this area have been reported. ${ }^{18-23}$ The blends are miscible when the difference in the $\mathrm{HV}$ content between the component polyesters is small, but immiscible when the difference becomes larger. Phase separation occurs in blends where the relative HV content (difference between the $\mathrm{HV}$ content of the component with the lowest $\mathrm{HV}$ and the average $\mathrm{HV}$ content of the blend) exceeds about $12 \%{ }^{21}$ In these studies, however, systematic analysis was restricted to the differences in HV content less than $22 \mathrm{~mol} \%$. The PHB blends with $\mathrm{PHB}-77 \% \mathrm{HV}^{19}$ and $\mathrm{PHV}^{23}$ are only the immiscible blends which have been investigated. Here, PHB-77\% $\mathrm{HV}$ and $\mathrm{PHV}$ indicate the $\mathrm{PHB}-\mathrm{HV}$ with $77 \% \mathrm{HV}$ and HV homopolymer, respectively. The behavior of blends with the intermediate $\mathrm{HV}$ difference has not been investigated. In addition, bacterial PHB-HV copolyesters, which might have a complex composition distribution, have been used as received. In this paper, we report results obtained for the blends of $\mathrm{P}(\mathrm{HB}-\mathrm{co}-\mathrm{HV})$ copolyesters, which were prepared by compositional fractionation of bacterial copolyesters and have a narrower composition distribution. In order to make a clear distinction between the compositionally fractionated copolyesters and the bacterial copolyesters with a complex composition distribution, the fractionated ones are abbreviated to $\mathrm{P}(\mathrm{HB}-\mathrm{co}-\mathrm{HV})$ instead of $\mathrm{PHB}-\mathrm{HV}$. In this paper, we attempt to understand the relations between various properties and composition distribution 
for PHB-HV copolymers. Thermal and crystallization behavior of the $\mathrm{P}(\mathrm{HB}-\mathrm{co}-\mathrm{HV})$ blends will be investigated and the results will be compared with those of as received bacterial PHB-HV copolyesters.

\section{EXPERIMENTAL}

\section{Bacterial Samples}

Four bacterial PHB-HV copolyesters were used in this study. Table I shows their sources and lot numbers. It has been concluded in the previous paper that the composition distribution of these bacterial copolyesters was extremely broad and/or has many peaks over a wide composition range. ${ }^{17}$

\section{Blend Samples}

A PHB homopolyester and ten copolyesters having different $\mathrm{HV}$ contents were used as the blend components. The molecular characteristics and preparation methods of these polyesters are shown in Table II. All the copolyesters except PHB-92\% HV were prepared by compositional fractionation of bacterial $\mathrm{PHB}-\mathrm{HV}$ copolyesters by using chloroform $/ n$-heptane mixed solvent. The fractionation procedure and the detailed characteristics of $\mathrm{P}(\mathrm{HB}-\mathrm{co}-\mathrm{HV})$ and $\mathrm{PHB}-\mathrm{HV}$ are described in the previous paper. ${ }^{17}$ PHB-92\% HV was isolated from Alcaligenes eutrophus (ATCC 17699) using valeric acid as a carbon source according to the procedure described elsewhere. ${ }^{24}$ This copolyester was used without fractionation. PHB was purchased from Aldrich Chemical Co. and used as received.

Blend samples were prepared by casting from $10 \mathrm{gl}^{-1}$ solutions in chloroform. The solvent was allowed to evaporate for 2 days, and the resultant films were dried for 2 days under vacuum. Eleven pairs of polyesters (see Table III) were blended in various proportions.

\section{Measurements}

DSC Thermograms were recorded using a Seiko DSC-20 equipped with a SSC-580 thermal controller.

Table I. Bacterial copolyesters used for fractionation

\begin{tabular}{|c|c|c|}
\hline Copolyester & Source & Lot number \\
\hline PHB-7\% HV & ICI & PSM-17 \\
\hline PHB-15\% HV & ICI & Po- 16 \\
\hline PHB- $22 \% \mathrm{HV}$ & Aldrich & DM8231ML \\
\hline
\end{tabular}

Film samples of $3-5 \mathrm{mg}$, which were sealed in aluminum pans, were first heated from room temperature to $195^{\circ} \mathrm{C}$ at a heating rate of $10^{\circ} \mathrm{Cmin}^{-1}$, followed by crystallization at $80^{\circ} \mathrm{C}$ over 2 weeks. The thermograms were measured by heating from $80^{\circ} \mathrm{C}$ to $200^{\circ} \mathrm{C}$ at a heating rate of $10^{\circ} \mathrm{C} \mathrm{min}^{-1}$, unless otherwise indicated. The melting temperatures $\left(T_{\mathrm{m}}\right)$ shown in this paper are taken as the DSC peak position.

Spherulite growth rates $(G)$ were measured by an Olympus BX90 polarized microscope equipped with a Mettler FP82HT hot stage. Film samples were first heated from room temperature to $195^{\circ} \mathrm{C}$ and then kept at $195^{\circ} \mathrm{C}$ for $1 \mathrm{~min}$. Subsequently, the samples were cooled to $80^{\circ} \mathrm{C}$ (crystallization temperature, $T_{\mathrm{c}}$ ) and were crystallized isothermally at $T_{\mathrm{c}}$. The spherulite radius of all the samples increases linearly with time. Spherulite growth rates were taken as the slope of the line obtained by plotting the spherulite radius against the crystallization time.

\section{RESULTS AND DISCUSSION}

Melting Behavior of Blends under Various Heating Rates

DSC melting thermograms of all the blends crystallized at $80^{\circ} \mathrm{C}$ showed multiple melting peaks. When we attempt to assign these peaks, we must distinguish between peaks arising from phase separated crystals and ones arising from crystals rearranged during heating in the DSC. By simply varying the heating rate, these can be distinguished. Figure 1 shows DSC melting thermograms obtained at various heating rates for blends of $50 / 50$ $\mathrm{PHB} / \mathrm{P}(\mathrm{HB}-\mathrm{co}-11 \% \mathrm{HV})$, and $25 / 75 \mathrm{PHB} / \mathrm{P}(\mathrm{HB}-\mathrm{co}-19 \%$ $\mathrm{HV})$. In the case of $\mathrm{PHB} / \mathrm{P}(\mathrm{HB}-\mathrm{co}-11 \% \mathrm{HV})$, the relative areas of two melting peaks vary with heating rate, indicating that the lower temperature peak is the melting peak of crystals formed at $T_{\mathrm{c}}$ while the higher one is that of crystals recrystallized during the DSC heating process. Therefore, the true melting temperature of the blend is given by the lower temperature peak. Such recrystallization behavior is commonly observed for semicrystalline polymers and has also reported for PHB. ${ }^{25}$

In the case of $\mathrm{PHB} / \mathrm{P}(\mathrm{HB}-\mathrm{co}-19 \% \mathrm{HV})$, three peaks were observed in the melting thermograms. The change of the heating rates has much effect on the relative proportion of the higher temperature peak, but has little effect on those of the lower and the middle temperature peaks. This behavior indicates that both of the lower and the middle temperature peaks are true melting

Table II. Characteristics of polyesters used as blend components

\begin{tabular}{|c|c|c|c|}
\hline Polyester & HV content $/ \%$ & $M_{n} \times 10^{5}$ & Preparation method \\
\hline $\mathrm{P}(\mathrm{HB}-c o-6 \% \mathrm{HV})$ & 6.1 & 1.5 & Fractionated from $\mathrm{PHB}-7 \% \mathrm{HV}$ \\
\hline $\mathrm{P}(\mathrm{HB}-c o-11 \% \mathrm{HV})$ & 11.3 & 0.75 & Fractionated from $\mathrm{PHB}-15 \% \mathrm{HV}$ \\
\hline $\mathrm{P}(\mathrm{HB}-\mathrm{co}-13 \% \mathrm{HV})$ & 13.3 & 1.7 & Fractionated from $\mathrm{PHB}-22 \% \mathrm{HV}$ \\
\hline $\mathrm{P}(\mathrm{HB}-\mathrm{co}-18 \% \mathrm{HV})$ & 17.8 & 1.6 & Fractionated from $\mathrm{PHB}-22 \% \mathrm{HV}$ \\
\hline $\mathrm{P}(\mathrm{HB}-\mathrm{co}-19 \% \mathrm{HV})$ & 18.5 & 1.2 & Fractionated from $\mathrm{PHB}-15 \% \mathrm{HV}$ \\
\hline $\mathrm{P}(\mathrm{HB}-c o-23 \% \mathrm{HV})$ & 22.6 & 2.1 & Fractionated from $\mathrm{PHB}-22 \% \mathrm{HV}$ \\
\hline $\mathrm{P}(\mathrm{HB}-c o-25 \% \mathrm{HV})$ & 25.3 & 0.49 & Fractionated from $\mathrm{PHB}-15 \% \mathrm{HV}$ \\
\hline $\mathrm{P}(\mathrm{HB}-c o-29 \% \mathrm{HV})$ & 28.6 & 1.0 & Fractionated from PHB- $22 \% \mathrm{HV}$ \\
\hline $\mathrm{P}(\mathrm{HB}-c o-34 \% \mathrm{HV})$ & 34.4 & 0.38 & Fractionated from $\mathrm{PHB}-22 \% \mathrm{HV}$ \\
\hline PHB-92\% HV & 92.4 & 1.7 & Isolated from $A$. eutrophus \\
\hline PHB & 0.0 & 1.7 & $\begin{array}{l}\text { Purchased from Aldrich } \\
\text { (JX12218HX) }\end{array}$ \\
\hline
\end{tabular}


Table III. Difference in HV content and phase behavior of blends

\begin{tabular}{lcc}
\hline \multicolumn{1}{c}{ Blend components } & $\begin{array}{c}\text { Difference in } \\
\text { HV content/\% }\end{array}$ & $\begin{array}{c}\text { Phase } \\
\text { behavior }\end{array}$ \\
\hline PHB/P(HB-co-6\% HV) & 6 & (i) \\
P(HB-co-6\% HV)/P(HB-co-13\% HV) & 7 & (i) \\
PHB/P(HB-co-11\% HV) & 11 & (i) \\
PHB/P(HB-co- $18 \%$ HV) & 18 & (i) \\
PHB/P(HB-co-29\% HV) & 29 & (i) \\
PHB/P(HB-co-19\% HV) & 19 & (ii) \\
PHB/P(HB-co- $23 \%$ HV) & 23 & (ii) \\
PHB/P(HB-co-34\% HV) & 34 & (ii) \\
P(HB-co-18\% HV)/P(HB-co-34\% HV) & 16 & (iii) \\
PHB/P(HB-co-25\% HV) & 25 & (iii) \\
PHB/PHB- $92 \%$ HV & 92 & (iv) \\
\hline
\end{tabular}

${ }^{a}$ (i): An isomorphous crystalline phase being formed from the miscible melt. (ii): Two crystalline phases observed in situations (i) and (iii) being formed from the miscible melt. (iii): A crystalline phase of the component polyester having the largest crystallization rate being partitioned from the miscible melt. (iv): Two crystalline phase similar to the pure components being formed from the immiscible melt.

peaks. Each of the peaks corresponds to a separate phase organized at crystallization temperature, $80^{\circ} \mathrm{C}$.

\section{Blend Samples Isothermally Crystallized at $80^{\circ} \mathrm{C}$}

Each of the binary blend systems analyzed here exhibited one of four distinct types of behavior. The detailed behavior were investigated for the typical four blend systems, $\mathrm{PHB} / \mathrm{P}(\mathrm{HB}-c o-11 \% \mathrm{HV}), \mathrm{PHB} / \mathrm{P}(\mathrm{HB}-\mathrm{co}-$ $19 \% \mathrm{HV}$ ), PHB/P(HB-co-25\% HV), and PHB/PHB$92 \% \mathrm{HV}$. For the other blend systems, only the data of $T_{\mathrm{m}}$ are shown.

(1) $P H B / P(H B-c o-11 \% \quad H V) \quad \mathrm{PHB} / \mathrm{P}(\mathrm{HB}-c o-11 \%$ $\mathrm{HV})$ blends seem to be miscible in the melt and isomorphous in the crystalline phase. The positions of DSC melting peaks are plotted against the blend-composition in Figure 2(a). Only the melting peaks ascribed to the crystals formed at $T_{\mathrm{c}}\left(=80^{\circ} \mathrm{C}\right)$ are shown in this figure. Each of the blends has one $T_{\mathrm{m}}$ which lies on a straight line connecting the $T_{\mathrm{m}}$ 's of PHB and P(HB-co-11\% HV). The polarized microscopy showed that the blends and the blend components similarly crystallized according to a spherulite morphology. Since the spherulite morphology is influenced considerably by precise crystallization conditions, ${ }^{13}$ it can not provide any valuable information on the phase structure. The spherulite growth rates, $G$, of these blends are shown in Figure 3(a). It was observed that the $G$ value is depressed by the addition of $\mathrm{P}(\mathrm{HB}-\mathrm{co}-\mathrm{HV})$. The $G$ value of the blends also lie on a straight line connecting the $G$ values of PHB and P(HB-co-11\% HV). The trends of the $G$ and $T_{\mathrm{m}}$ values correspond to those expected for pure $\mathrm{P}(\mathrm{HB}-\mathrm{co}-\mathrm{HV})$ copolymers containing $0-11 \mathrm{~mol} \% \mathrm{HV}$. We cannot distinguish these blends from $\mathrm{P}(\mathrm{HB}-\mathrm{co}-\mathrm{HV})$ copolymers with a narrow composition distribution. The melting and crystallization behavior indicates that PHB and $\mathrm{P}(\mathrm{HB}-\mathrm{co}-11 \% \mathrm{HV})$ form miscible melt followed by cocrystallization (isomorphism).

(2) $P H B / P(H B-c o-25 \% \quad H V)$ In $\mathrm{PHB} / \mathrm{P}(\mathrm{HB}-c o-$ $25 \% \mathrm{HV}$ ) blends compositional partition is likely to occur during the growth of spherulites. Figures 2(b) and 3(b) show $T_{\mathrm{m}}$ and $G$ of these blends. These blends show a single $T_{\mathrm{m}}$, which is intermediate value between those of PHB and $\mathrm{P}(\mathrm{HB}-\mathrm{co}-25 \% \mathrm{HV})$ although it is close
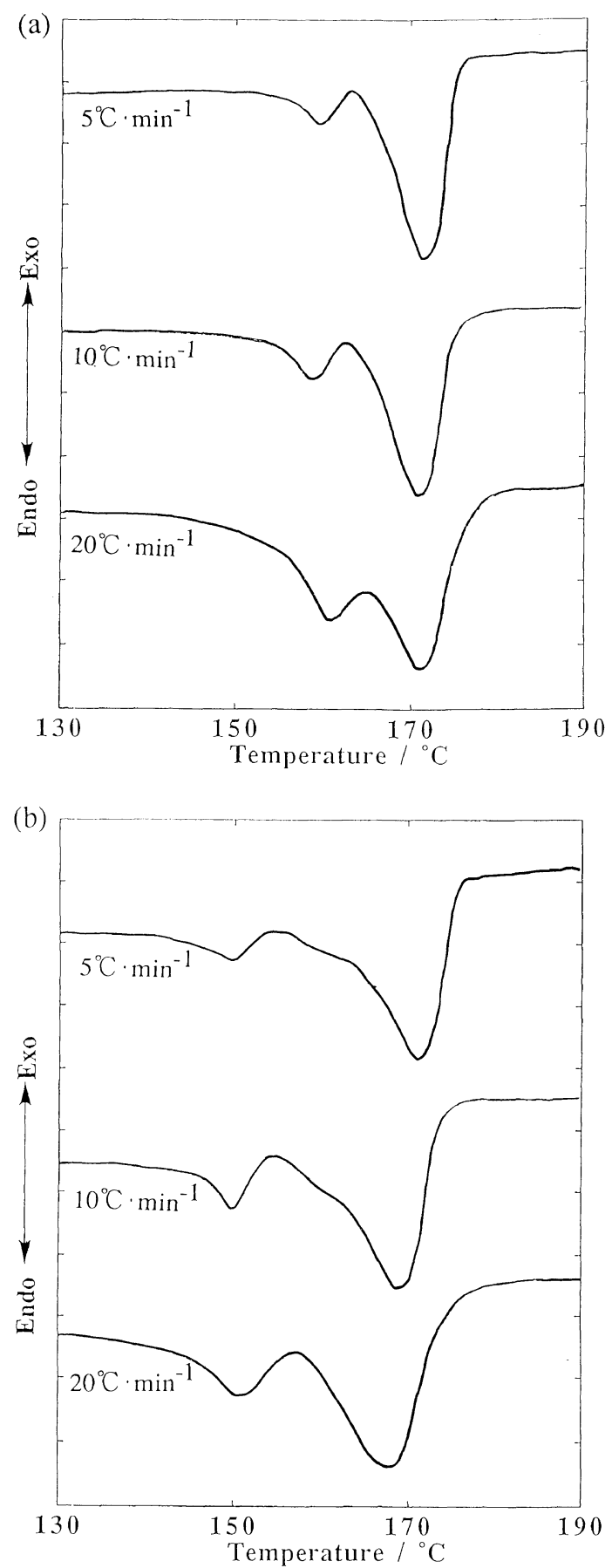

Figure 1. DSC melting thermograms obtained at various heating rate for (a) a blend of 50/50 PHB/P(HB-co-11\% HV), and (b) a blend of $25 / 75 \mathrm{PHB} / \mathrm{P}(\mathrm{HB}-\mathrm{co}-19 \% \mathrm{HV})$ crystallized at $80^{\circ} \mathrm{C}$.

to that of pure PHB. A spherulite growth rate of the blends is also close to that of PHB. The $T_{\mathrm{m}}$ and $G$ values indicate crystallization of a PHB phase. Any melting peak indicating the formation of $\mathrm{P}(\mathrm{HB}-\mathrm{co}-\mathrm{HV})$ crystals was not observed. The depression of the $T_{\mathrm{m}}$ and $G$ of PHB crystals and the absence of P(HB-co-25\% HV) crystals suggest the intermolecular interaction between PHB and P(HB-co-25\% HV).

These results are consistent with the assumption that part of PHB molecules are partitioned from the miscible melt to form the crystalline phase: during the growth of PHB crystals, the $\mathrm{P}(\mathrm{HB}-\mathrm{co}-25 \% \mathrm{HV})$ molecules are ejected to the amorphous region forming a homogene- 

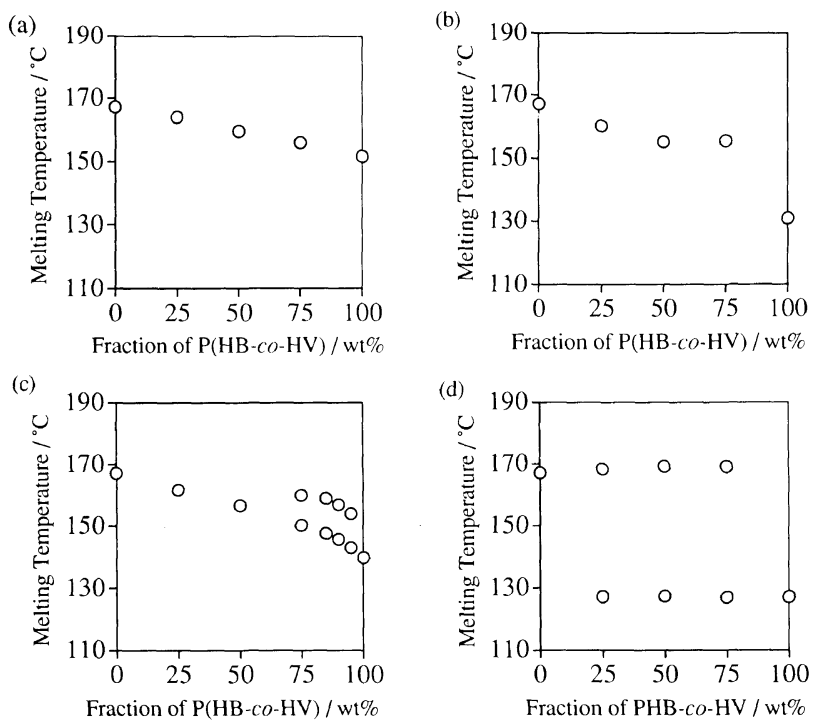

Figure 2. Melting temperatures of blends of (a) $\mathrm{PHB} / \mathrm{P}(\mathrm{HB}-\mathrm{co}-11 \%$ $\mathrm{HV}$ ), (b) PHB/P(HB-co-25\% HV), (c) PHB/P(HB-co-19\% HV), and (d) $\mathrm{PHB} / \mathrm{P}(\mathrm{HB}-\mathrm{co}-92 \% \mathrm{HV})$ crystallised at $80^{\circ} \mathrm{C}$.
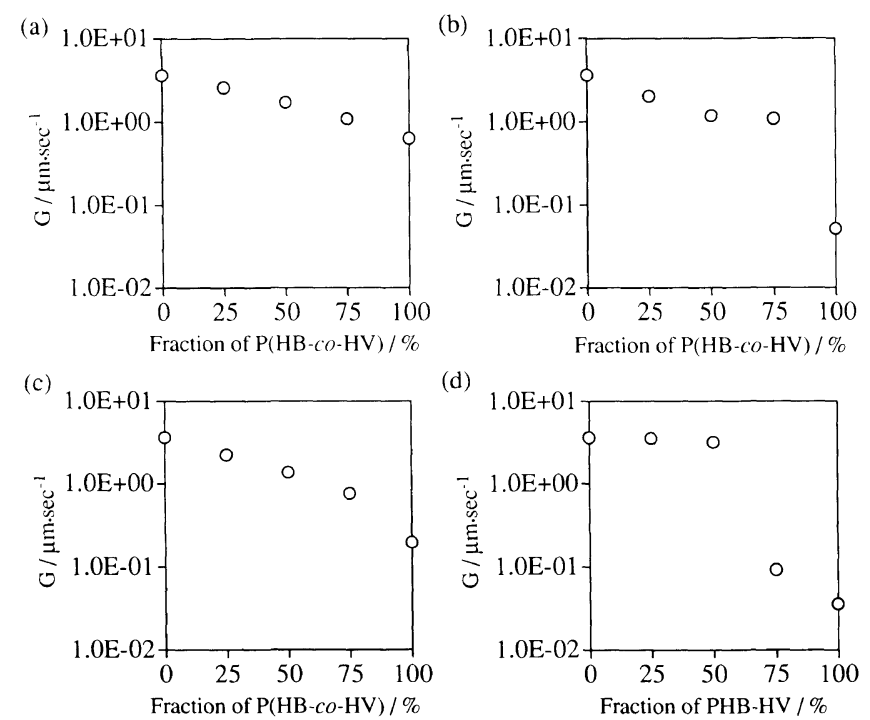

(d)

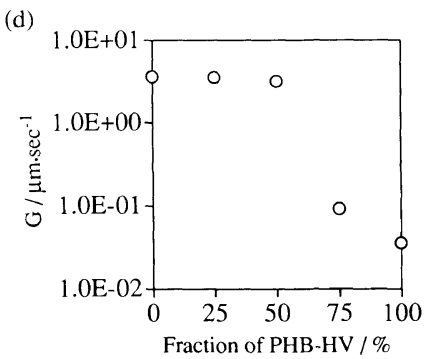

Figure 3. Spherulite growth rate of blends of (a) $\mathrm{PHB} / \mathrm{P}(\mathrm{HB}-\mathrm{co}-11 \%$ HV), (b) PHB $/ \mathrm{P}(\mathrm{HB}-\mathrm{co}-25 \% \mathrm{HV})$, (c) $\mathrm{PHB} / \mathrm{P}(\mathrm{HB}-\mathrm{co}-19 \% \mathrm{HV})$, and (d) $\mathrm{PHB} / \mathrm{P}(\mathrm{HB}-\mathrm{co}-92 \% \mathrm{HV})$ crystallised at $80^{\circ} \mathrm{C}$.

ous solution with uncrystallized PHB molecules. The resultant morphology is similar to the model assumed for the miscible blends of $\mathrm{PHB} /$ poly(ethylene oxide) (PEO). ${ }^{26,27}$ In the case of the PHB/PEO blend system, crystallization of $\mathrm{PEO}$ is prevented by keeping the $T_{\mathrm{c}}$ higher than the $T_{\mathrm{m}}$ of PEO. In PHB $/ \mathrm{P}(\mathrm{HB}-\mathrm{co}-25 \% \mathrm{HV})$ blends, the $T_{\mathrm{c}}$ was set sufficiently low for the crystallization of $\mathrm{P}(\mathrm{HB}-\mathrm{co}-25 \% \mathrm{HV})$. Kinetic factors may disturb the crystallization of $\mathrm{P}(\mathrm{HB}-\mathrm{co}-25 \% \mathrm{HV})$. Since the $G$ value of PHB is much larger than that of $\mathrm{P}(\mathrm{HB}-$ co- $25 \% \mathrm{HV}$ ), only the PHB lamellas may grow in the initial stage. During this stage, the $\mathrm{P}(\mathrm{HB}-\mathrm{co}-25 \% \mathrm{HV})$ molecules may be trapped in the interlamellar regions.

(3) $P H B / P(H B-c o-19 \% \quad H V) \quad \mathrm{PHB} / \mathrm{P}(\mathrm{HB}-19 \%$ $\mathrm{HV}$ ) blends containing more than $50 \mathrm{wt} \%$ copolyester show a crystallization behavior combined that of $\mathrm{PHB} / \mathrm{P}(\mathrm{HB}-\mathrm{co}-11 \% \mathrm{HV})$ and of $\mathrm{PHB} / \mathrm{P}(\mathrm{HB}-\mathrm{co}-25 \%$ $\mathrm{HV}$ ). Figures 2(c) and 3(c) show the $T_{\mathrm{m}}$ and $G$ values.
The blends containing less than $50 \mathrm{wt} \%$ copolyester show a single $T_{\mathrm{m}}$, while the blends containing more than $75 \mathrm{wt} \%$ copolyester have two $T_{\mathrm{m}}$ 's. The behavior of the formar blends are similar to that of the $\mathrm{PHB} / \mathrm{P}(\mathrm{HB}-\mathrm{co}-$ $11 \% \mathrm{HV}$ ) blends, which forms the miscible melt and the isomorphous crystals. The lower temperature $T_{\mathrm{m}}\left(T_{\mathrm{m} 1}\right)$ of the latter blends lies on the same line as the $T_{\mathrm{m}}$ of the former blends. The higher temperature $T_{\mathrm{m}}\left(T_{\mathrm{m} 2}\right)$ of the latter blends is close to the $T_{\mathrm{m}}$ of PHB. The blendcompositional dependence of the $T_{\mathrm{m} 2}$ is similar to that of the $T_{\mathrm{m}}$ of $\mathrm{PHB} / \mathrm{P}(\mathrm{HB}-\mathrm{co}-25 \% \mathrm{HV})$. The results suggest both the $\mathrm{PHB}$ and the isomorphous crystals are formed from the miscible melt of the PHB $/ \mathrm{P}(\mathrm{HB}-\mathrm{co}-25 \% \mathrm{HV})$ blends containing more than $75 \mathrm{wt} \%$ copolyester.

(4) $\mathrm{PHB} / \mathrm{PHB}-92 \% \mathrm{HV} \quad \mathrm{PHB} / \mathrm{PHB}-92 \% \mathrm{HV}$ blends show typical behavior of immiscible polymer blends. Figures 2(d) and 3(d) show the results from these blends. All the blends were characterized by two melting temperatures. The higher- and the lower-temperature peaks gives the $T_{\mathrm{m}}$ values very close to those obtained from the pure component polyesters, PHB and PHB$92 \% \mathrm{HV}$, respectively. Each blend component gives little influence on the melting behavior of the blend partner. These results provide evidence for phase separation in the melt and the crystalline phases. Polarized micrograph also showed phase separation. One of the melt phase formed the spherulites and the other melt phase formed the islands of melt in the intraspherulite regions in the initial stage. All the spherulites in the blend grew in the same linear radial growth rate. The $G$ values of these spherulites are shown in Figure 3(d). The $G$ value is similar to that of PHB or PHB-92\% HV. In the second stage at a given $T_{\mathrm{c}}$, the islands of melt became separated spherulites. These results support the assumption of phase separation. We couldn't determine the $G$ values of the separated spherulites grown in the second stage since they are small and/or indistinct.

Other Blends The blend systems shown above indicate the presence of four situations that might arise for $\mathrm{PHB} / \mathrm{P}(\mathrm{HB}-\mathrm{co}-\mathrm{HV})$ and $\mathrm{P}(\mathrm{HB}-c o-\mathrm{HV}) / \mathrm{P}(\mathrm{HB}-c o-\mathrm{HV})$ blends. These are:

(i) An isomorphous crystalline phase being formed from the miscible melt.

(ii) Two crystalline phases observed in situations (i) and (iii) being formed from the miscible melt.

(iii) A crystalline phase of the component polyester having the largest $G$ value being partitioned from the miscible melt.

(iv) Two crystalline phase similar to the pure components being formed from the immiscible melt.

Situation (i) is discriminated from the others by the blend-composition dependence of $T_{\mathrm{m}}$ and $G$ values, which lie on the respective straight lines connecting the $T_{\mathrm{m}}$ and $G$ values of the pure components. Situation (iii) is discriminated by the $T_{\mathrm{m}}$ and $G$ values which are close to those of the component having the largest $G$ value. The blends belonging to situation (ii) show two $T_{\mathrm{m}}$ values corresponding to those of situations (i) and (iii). The blends belonging to situation (iv) show two $T_{\mathrm{m}}$ values which are very close to those of the components.

We have classified eleven blend systems into these four situations by analyzing $T_{\mathrm{m}}$. Figure 4 shows the $T_{\mathrm{m}}$ values 


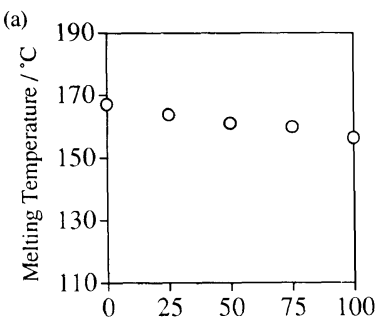

Fraction of $\mathrm{P}(\mathrm{HB}-\mathrm{co}-6 \% \mathrm{HV}) / \mathrm{wt} \%$
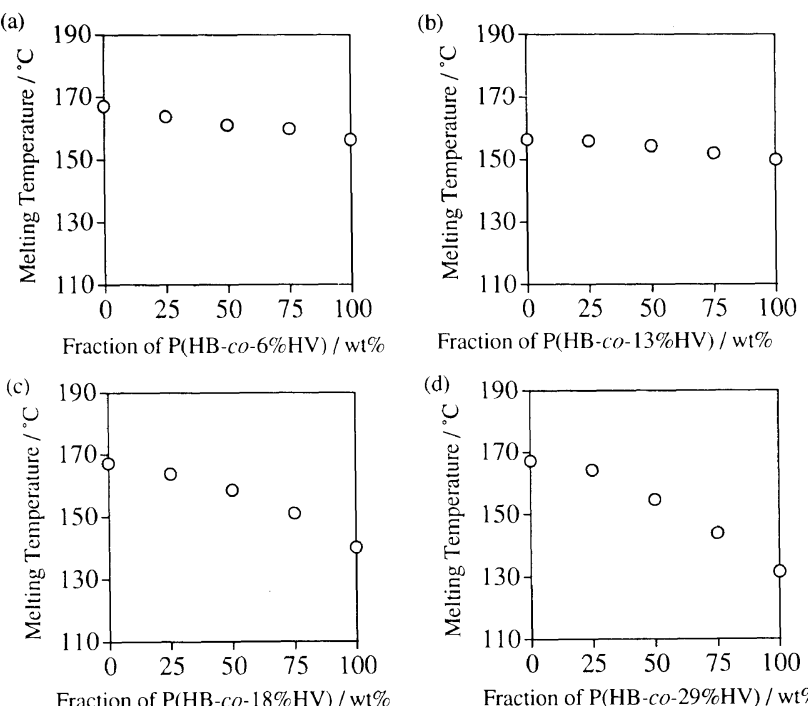

Fraction of $\mathrm{P}(\mathrm{HB}-\mathrm{co}-13 \% \mathrm{HV}) / \mathrm{wt} \%$
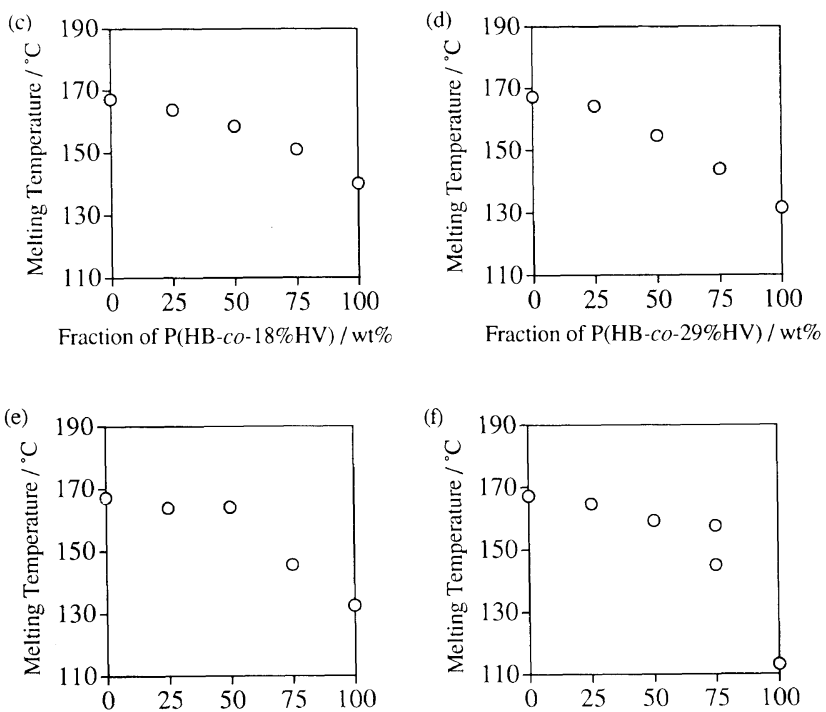

Fraction of $\mathrm{P}(\mathrm{HB}-\mathrm{co}-23 \% \mathrm{HV}) / \mathrm{wt} \%$
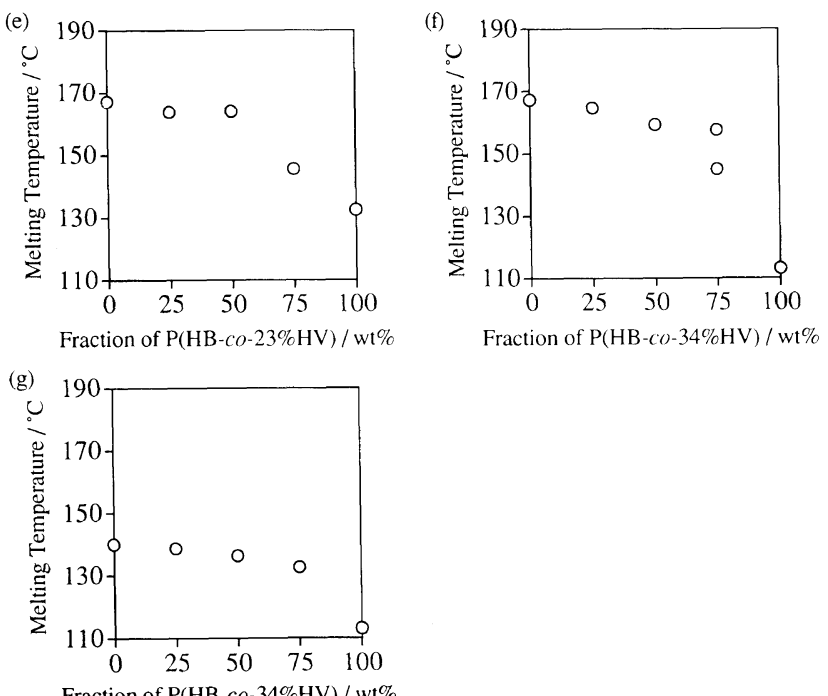

Fraction of $\mathrm{P}(\mathrm{HB}-\mathrm{co}-34 \% \mathrm{HV}) / \mathrm{wt} \%$

Miscible blends may also show situation (iv) when the components are miscible but not so intimate. It was reported that miscible blends of $\mathrm{PHB} / \mathrm{PEO}$ exhibited behavior similar to situation (iv) ${ }^{26,27}$ Immiscible blends surely show the behavior of situation (iv).

\section{Properties of Bacterial $P(H B-c o-H V) s$ with Complex Composition}

On the basis of the above mentioned results obtained for blends, we now discuss the effect of complex composition distribution on crystallization and melting behaviors of bacterial PHB-HV copolymers. The fractionation of four PHB-HV's, $\mathrm{PHB}-7 \% \mathrm{HV}, \mathrm{PHB}-15 \%$ $\mathrm{HV}$, PHB-19\% HV, and PHB-22\% HV, have been reported in the previous paper. ${ }^{17}$ PHB-7\% $\mathrm{HV}$ and PHB-15\% HV can be regarded as binary blends of $95 / 5$ $\mathrm{P}(\mathrm{HB}-\mathrm{co}-6 \% \mathrm{HV}) / \mathrm{P}(\mathrm{HB}-\mathrm{co}-16 \% \mathrm{HV})$ and $50 / 50 \mathrm{P}(\mathrm{HB}-$ co-10\% HV) $/ \mathrm{P}(\mathrm{HB}-c o-20 \% \mathrm{HV})$. $\mathrm{PHB}-19 \% \mathrm{HV}$ can be regard as a copolymer with a very broad composition distribution. Since the difference in the HV content among the components is less than $15 \%$, these blends are classified into situation (i), where the components are miscible in the melt and form the isomorphous crystals. The crystallization and melting behavior of these bacterial PHB-HV's are indistinguishable from those of pure copolyesters of $\mathrm{P}(\mathrm{HB}-\mathrm{co}-7 \% \mathrm{HV}), \mathrm{P}(\mathrm{HB}-\mathrm{co}-15 \%$ $\mathrm{HV}$ ), and $\mathrm{P}(\mathrm{HB}-\mathrm{co}-19 \% \mathrm{HV})$, respectively. The apparent behavior of these PHB-HV's is consistent with that expected for PHB-HV with average compositions.

PHB $-22 \% \mathrm{HV}$ is regarded as a ternary blend of $25 / 50 / 25 \mathrm{P}(\mathrm{HB}-\mathrm{co}-13 \% \mathrm{HV}) / \mathrm{P}(\mathrm{HB}-\mathrm{co}-20 \% \mathrm{HV}) / \mathrm{P}(\mathrm{HB}-$ co-30\% HV). The largest differences in the HV content is about $17 \%$. PHB- $22 \% \mathrm{HV}$ shows two distinct $T_{\mathrm{m}}$ 's corresponding to those of pure $\mathrm{P}(\mathrm{HB}-\mathrm{co}-13 \% \mathrm{HV})$ and $\mathrm{P}(\mathrm{HB}-\mathrm{co}-20 \% \mathrm{HV})$. This $\mathrm{PHB}-\mathrm{HV}$ sample is classified into situation (iii). The crystallization and melting behavior give $\mathrm{PHB}-22 \% \mathrm{HV}$ an appearance of $\mathrm{P}(\mathrm{HB}-$ $c o-\mathrm{HV})$ with lower $\mathrm{HV}$ content. We can not obtain the accurate properties of $\mathrm{P}(\mathrm{HB}-\mathrm{co}-22 \% \mathrm{HV})$ by the analysis of this PHB-HV sample.

Although bacterial PHB-HV's have a complex composition distribution, most PHB-HV's show the behavior of situation (i) and are indistinguishable from that of pure P(HB-co-HV)'s. However, some PHB-HV's, which have extremely broad composition distribution, show behavior different from that of pure $\mathrm{P}(\mathrm{HB}-\mathrm{co}-$ HV)'s. In the latter cases, only the crystalline phase of the component having larger spherulite growth rate is formed (situation (iii)) or more than two crystalline phases are formed (situations (ii) and (iv)). We need to treat these PHB-HV samples with careful consideration. Especially in the situation (iii), we are apt to mistake the properties of the partitioned crystals for those of the isomorphous crystals. A single $T_{\mathrm{m}}$ is insufficient to confirm the isomorphous crystals.

\section{REFERENCES} factors which determine the phase behavior. Situations (i), (ii), and (iii) arise from the miscible blends. The factor discriminating between situations (i) and (iii) is thought to be the difference in the $G$ values between the component polyesters. The small difference gives rise to the formation of isomorphous crystals (situation (i)), while the large one cause partitioning (situation (iii)).

1. P. A. Holmes, Phys. Technol., 16, 32 (1985).

2. Y. Doi, A. Tamaki, M. Kunioka, and M. Soga, Appl. Microbiol. Biotechnol., 28, 330 (1988).

3. Y. Doi, "Microbial Polyesters"; VHC Publishers Inc., New York, N.Y., 1990

4. P. J. Barham, P. Barker, and S. J. Organ, FEMS Microbiol. Rev., 
103, 189 (1992).

5. Y. Inoue and N. Yoshie, Prog. Polym. Sci., 17, 571 (1992).

6. T. L. Bluhm, G. K. Hamer, R. H. Marchessault, C. A. Fyfe, and R. P. Veregin, Macromolecules, 19, 2871 (1986).

7. M. Kunioka, A. Tamaki, and Y. Doi, Macromolecules, 22, 694 (1989).

8. S. J. Organ, Polymer, 34, 2175 (1993).

9. N. Kamiya, M. Sakurai, Y. Inoue, R. Chûjô, and Y. Doi, Macromolecules, 24, 2178 (1991).

10. N. Yoshie, M. Sakurai, Y. Inoue, and R. Chûjô, Macromolecules, 25, 2046 (1992).

11. M. Scandola, G. Ceccorulli, M. Pizzoli, and M. Gazzano, Macromolecules, 25, 1405 (1992).

12. H. Mitomo, N. Morishita, and Y. Doi, Macromolecules, 26, 5809 (1993).

13. S. J. Organ and P. J. Barham, J. Mater. Sci., 26, 1368 (1991).

14. H. Bauer and A. J. Owen, Collect Polym. Sci., 266, 241 (1988).

15. M. Scandola, G. Ceccorulli, and Y. Doi, Int. J. Biol. Macromol., 12, $112(1990)$.
16. Y. Doi, Y. Kanesawa, M. Kunioka, and T. Saito, Macromolecules, 23, 26 (1990).

17. N. Yoshie, H. Menju, H. Sato, and Y. Inoue, Macromolecules, in press.

18. R. H. Marchessault, T. L. Bluhm, Y. Deslandes, G. K. Hamer, W. J. Orts, P. R. Sundararajan, and M. G. Taylor, Maclomol. Chem., Macromol. Symp., 235 (1988).

19. Y. Kumagai and Y. Doi, Polym. Degrad. Stab., 37, 253 (1992)

20. S. J. Organ and P. J. Barham, Polymer, 34, 459 (1993).

21. S. J. Organ, Polymer, 35, 86 (1994)

22. H. Satoh, N. Yoshie, and Y. Inoue, Polymer, 35, 286 (1994).

23. R. P. Pearce and R. H. Marchessault, Macromolecules, 27, 3869 (1994).

24. Y. Doi, A. Tamaki, M. Kunioka, and K. Soga, Appl. Microbiol. Biotechnol., 28, 330 (1988).

25. S. J. Organ and P. J. Barham, Polymer, 34, 2169 (1993).

26. M. Avella and E. Martuscelli, Polymer, 29, 1731 (1988).

27. M. Avella, E. Martuscelli, and P. Greco, Polymer, 32, 1647 (1991). 